\title{
A Novel Low-Energy Ventilative Cooling System for Sustainable Built Environment
}

\author{
Hassam Nasarullah Chaudhry* \\ School of Energy, Geoscience, Infrastructure and Society, Heriot-Watt University, P O Box: 294 345, Dubai, UAE
}

\begin{abstract}
A numerical investigation into determining the thermal and ventilation capability of wind towers integrated with the heat pipe technology was carried out in this work. The water-charged copper heat pipes were systematically arranged in a horizontal orientation and integrated inside a modern roof-mounted wind tower. Water was used as the working fluid instead of synthetic refrigerants in order to make the system carbon-neutral alongside maintaining the indoor air quality of the built environment. The three-dimensional Reynolds-Averaged Navier-Stokes (RANS) equations along with the momentum, continuity and energy equations were solved using the commercial Computational Fluid Dynamics (CFD) ANSYS code for velocity and pressure field simulations. Using the inlet wind speeds ranging from $1 \mathrm{~m} / \mathrm{s}$ to $5 \mathrm{~m} / \mathrm{s}$, the results of the study showed that the proposed cooling system was capable of meeting the regulatory fresh air intake requirements per occupant of $10 \mathrm{~L} / \mathrm{s}$. In addition, the findings determined that a passive cooling capacity of up to $11 \mathrm{~K}$ was achievable when the system was subjected to inlet temperatures of $310 \mathrm{~K}$ or $37^{\circ} \mathrm{C}$. The work characterised the sustainable operation of wind tower in delivering energy-free ventilative cooling in regions encompassing hot and dry climatic conditions. The technology presented in this work is currently under an Intellectual Property (IP) protection (GB1321709.6).
\end{abstract}

Keywords: Airflow; Computational Fluid Dynamics; Heat Pipe; Ventilation; Wind Tower

\section{Introduction}

According to the World Business Council for Sustainable Development (WBCSD), buildings account for up to $40 \%$ of the world's energy use [1]. Hence, the building sector accounts for a large proportional of primary energy consumption in most countries. Heating Ventilation and Air Conditioning (HVAC) systems account for up to $60 \%$ of domestic buildings energy consumption [2]. Increasing criterions in indoor environmental quality has led to greater energy consumption values in the HVAC sector. As a result, any novel concept or technology that assists in reducing a building's power consumption will encompass a positive result on its overall energy performance [3].

\begin{abstract}
Natural ventilation systems such as wind towers can still be classified as carbon-neutral passive cooling devices unlike the rest since they incorporate no external electricity consumption in comparison with other cooling strategies Wind towers have been in existence in various forms for centuries as a nonmechanical means of providing indoor ventilation. Commercial wind towers can be integrated into the designs of new buildings, to provide thermal comfort without the use of electrical energy [3-5]. Numerical studies [6] have shown that wind driven force is the primary driving force for the wind tower device, providing $76 \%$ more indoor ventilation than buoyancy driven forces. Figure 1 displays the different types of traditional wind towers depending on their number of openings.
\end{abstract}

${ }^{*}$ Corresponding author

E-mail: H.N.Chaudhry@hw.ac.uk

(C) 2016 International Association for Sharing Knowledge and Sustainability

DOI: $10.5383 /$ swes.8.01.005 

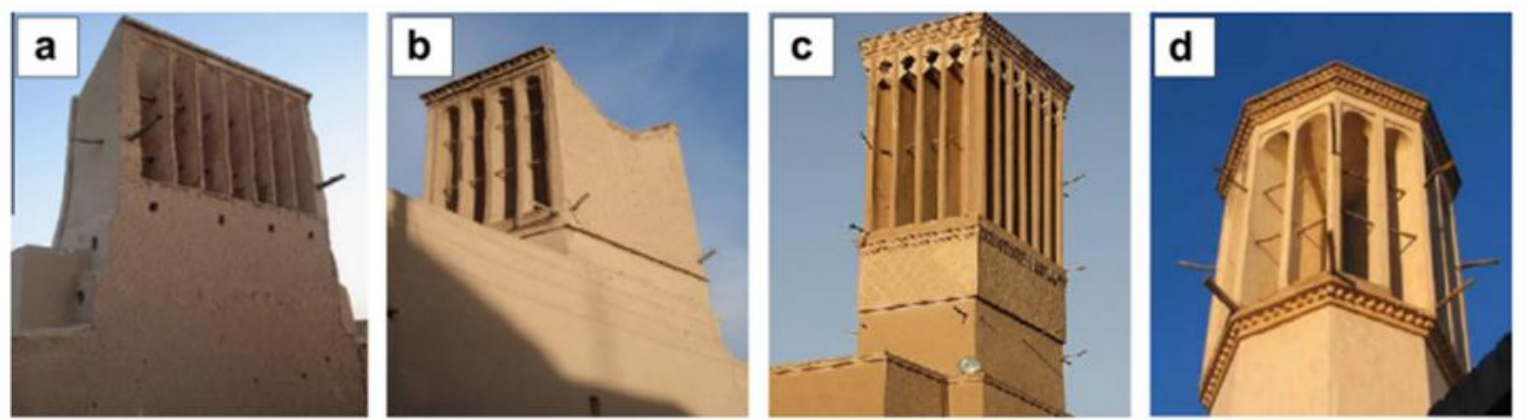

Figure 1 Traditional Wind Towers with Different Number of Openings: (A) One-Sided (B) Two-Sided (C) Four-Sided (D) Octahedral [7]

Despite the energy saving potential of wind towers, research into determining their passive cooling capabilities which depend mainly on the ambient macro climate and the structural design itself are inadequate. In order to confront the issue, there is a need for incorporating heat transfer mechanisms within natural ventilation systems in order to carry out the cooling duty. If integrated with heat pipes as heat transfer devices, the overall effectiveness of natural ventilation technology can be enhanced in terms of providing adequate indoor temperatures. Heat pipes function on a closed-loop heat transfer cycle without requiring external electricity for its operation, thereby making itself entirely adaptable for use within natural ventilation systems. Retrofitting heat pipes into heat exchangers for the purpose of pre-cooling in wind towers can potentially become an important economic consideration since the utility of heat pipes for environmental management is cost effective and environmentally sound. Previous literature involving wind tower systems as an energy efficient source for providing natural ventilation is extensive. Different cooling techniques were highlighted and integrated with wind tower systems to improve its thermal performance [6, 7]. Key parameters including the ventilation rates and temperature were evaluated in order to determine the viability of implementing the devices for their respective use. The temperature reductions are found to be in the range of $12-15 \mathrm{~K}$ Wetted interior surfaces fitted within wind towers have also proven to be effective in reducing internal air temperatures with reductions up to $17.6 \mathrm{~K}$ obtained from relevant works [8, 9]. Numerous investigations have been carried out on commercial wind towers and its operating louver angles in order to meet the delivery rate for fresh air intake. Previous works have depicted the capability of the device to meet the British Standard (B55925:1991) requirements of 20Pa for the minimum ventilation rates [10]. For various influencing input parameters, the optimum angle for efficient performance of wind tower louvers is found to be $35^{\circ}$, which will therefore be incorporated in the present work [11, 12]. This study carries out a computational investigation on the impact of the heat pipe arrangement within the passive terminals of a wind tower device in order to comprehend its effect on the flow and thermal parameters. Furthermore, the performance of the heat pipe-integrated wind tower is compared with a standard wind tower model without the heat pipes. For a valid comparison, both models incorporated identical internal volume and component configuration such as the louvers and wall thickness.

\section{COMPUTATIONAL DOMAIN}

Figure 2 displays a schematic of the wind tower model with an internal cross sectional area of $1 \mathrm{~m} 2$ and height of $1 \mathrm{~m}$, a typical size for a roof mounted wind tower system. Louvers located at the wind tower opening were angled at $45^{\circ}$. The louvers allowed the passage of airflow to the wind tower, while providing a measure of protection against the rain, direct sunlight and other elements.
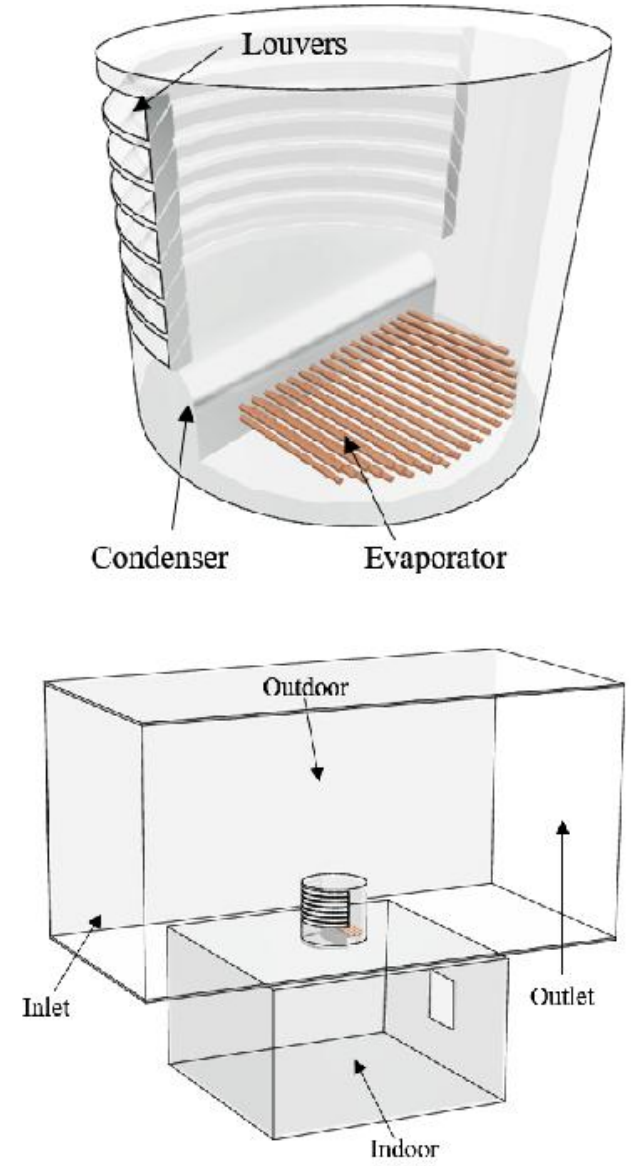

Figure 2 Schematic of the Circular Wind Tower Model with the Horizontal Heat Pipe Configuration 
The heat exchanger with the thermal cycle loop was located at the bottom section of the wind tower model. This section was equally divided into two parts; evaporator and condenser sections. The evaporator section consisted of 50 water-charged heat pipes with an outer diameter of $20 \mathrm{~mm}$ with length ranging from $40-50 \mathrm{~mm}$. The pitch diameter between the heat pipes was $50 \mathrm{~mm}$. The heat pipe fluid was pressurized to its saturation point at $20^{\circ} \mathrm{C}$ or $293 \mathrm{~K}$. Inlet axial mass flow rate values were $1.04 \times 10^{-2} \mathrm{~kg} / \mathrm{s}$ for water which was obtained from the analytical model at the applied specific heat flux and the outlet gauge pressure was set to zero.The cooling technique incorporated the operating capability of a low energy heat source and a cold sink position to be integrated into the passive terminals, thus optimising the cooling duty. In order to evaluate of the integration of the proposed cooling technology into buildings, the system is mounted centrally on top of a $5 \times 5 x$ $3 \mathrm{~m}^{3}$ empty domain which represents a small room. A $1 \times 1 \mathrm{~m} 2$ opening is created on the leeward wall of the room to exhaust the stale air out from the space. The ventilation and thermal performance of the wind tower configuration is investigated under external wind speeds of the range 1 to $5 \mathrm{~m} / \mathrm{s}$.

\subsection{Solution Methods and Boundary Conditions}

The three-dimensional Reynolds-Averaged Navier-Stokes (RANS) equations along with the momentum, continuity and energy equations were solved using the commercial CFD code for the velocity and pressure field simulations. The model employs the control-volume technique and the Semi-Implicit Method for Pressure-Linked Equations (SIMPLE) velocitypressure coupling algorithm with the second order upwind discretisation. The standard $k-e$ transport model which is frequently used for incompressible flows was used to define the turbulence kinetic energy and flow dissipation rate within the model [13]. The turbulence kinetic energy, $k$, and its rate of dissipation, $e$, were obtained from the following transport equations formulated in equation 1 and equation 2.

$\frac{\partial}{\partial t}(\rho k)+\frac{\partial}{\partial x_{i}}\left(\rho k u_{i}\right)=\frac{\partial}{\partial x_{j}}\left[\left(\mu+\frac{\mu_{t}}{\sigma_{k}}\right) \frac{\partial k}{\partial x_{j}}\right]+G_{k}+G_{b}-\rho \epsilon-Y_{M}+$ $S_{k}$

(Equation 1)

$\frac{\partial}{\partial t}(\rho e)+\frac{\partial}{\partial x_{i}}\left(\rho e u_{i}\right)=\frac{\partial}{\partial x_{j}}\left[\left(\mu+\frac{\mu_{t}}{\sigma_{e}}\right) \frac{\partial e}{\partial x_{i}}\right]+C_{1 e} \frac{e}{k}\left(G_{k}+C_{3 e} G_{b}\right)-$ $C_{2 \epsilon} \rho \frac{e^{2}}{k}+S_{e}$

(Equation 2)

Where; $\boldsymbol{G}_{\boldsymbol{k}}$ represents the generation of turbulence kinetic energy due to the mean velocity gradients, $\boldsymbol{G}_{\boldsymbol{b}}$ represents the generation of turbulence kinetic energy due to buoyancy. $\boldsymbol{Y}_{M}$ represents the contribution of fluctuating dilatation in compressible turbulence to the overall dissipation rate. $C_{1 e}, C_{2 e}$ and $C_{3 e}$ are constants, $\sigma_{k}$ and $\sigma_{e}$ are the turbulent Prandtl numbers for $\boldsymbol{k}$ and $\boldsymbol{e} . \boldsymbol{S}_{\boldsymbol{k}}$ and $\boldsymbol{S}_{\boldsymbol{e}}$ are the user-defined source terms. The geometry of the test room (micro climate) with the height, width, and length of $3 \mathrm{~m}, 6 \mathrm{~m}$, and $6 \mathrm{~m}$ representing a small sized classroom of 20 occupants [12] was used for the computational analysis.An enclosure was created to represent the external wind environment (macro climate). The enclosure with a height, width, and length of $8 \mathrm{~m}, 16 \mathrm{~m}$, and $16 \mathrm{~m}$ creating a direct interface through the geometry. The enclosure (the flow domain) was set at a distance from the geometry to avoid reversed flow in the region [14]. The boundary conditions for the CFD model are shown in Table 1 .

Table 1 CFD Model Boundary Conditions

\begin{tabular}{ll}
\hline Property & Value \\
\hline Geometry & Solid \\
Enclosure & Fluid (air) \\
Velocity inlet (m/s) & $1,2,3,4,5$ \\
Pressure outlet & Atmospheri \\
& $\mathrm{c}$ \\
Viscous model & k-epsilon \\
& $($ equation \\
Near-Wall treatment & $(2))$ \\
Velocity formulation & Standard \\
Time & Function \\
Gravity & Absolute \\
External Temperature (K) & Steady \\
\hline
\end{tabular}

\subsection{Grid Verification}

The meshed model comprised of 1.1 million unstructured elements with slow transition to obtain a balance between the run time and the resolution in the channel axial direction. The relevance centre was set as coarse with slow transition and a fixed element size of $0.10 \mathrm{~m}$ was set on the channel walls to compromise for nominal computation. The complete computational domain was split and refined in two particular areas, the wind tower channel and the immediate surrounding zone. The grid verification process increased the number of elements by 933,719 . Each stage was continued until an acceptable compromise was reached between: number of elements; computational time to solve; and the posterior error indication (Figure 3). At 1,086,510 elements the error indication between refinements was at its lowest in the final two stages; coupled with the computational time, made it an acceptable compromise.

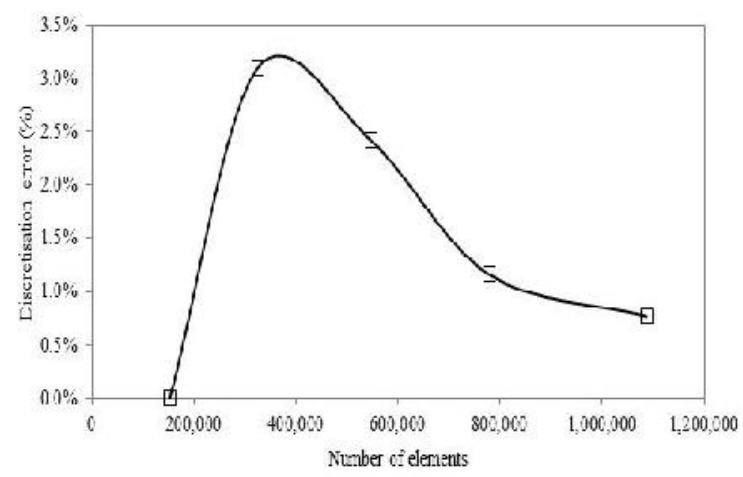

Figure 3 Error Reductions through Consecutive H-Adaption Method [15] 


\section{Results and Discussion}

The computational model involving the macro climate was run with wind speeds between $1 \mathrm{~m} / \mathrm{s}$ and $5 \mathrm{~m} / \mathrm{s}$. Velocity and pressure contour plots were used to assess the ventilation performance of each configuration. The wind tower was located centrally within the micro climate. The center of the wind tower was located directly above the test room. Vertical distance at which the sample points were taken was $1.5 \mathrm{~m}$ with the additional point taken at $2.75 \mathrm{~m}$ (diffuser level).
With reference to Figure 4, the airflow distribution inside the test room model with a one-sided circular wind tower integrated heat pipes is obtained. For an external wind speed of $4 \mathrm{~m} / \mathrm{s}$, average air velocity of $0.67 \mathrm{~m} / \mathrm{s}$ inside the geometry interior was obtained which is $8.21 \%$ lower compared to the standard wind tower model. Furthermore, the average velocity measured below the diffuser is reduced by $11.98 \%$. This was expected, as the air stream speed is slightly reduced after passing through the horizontal heat pipe configuration.
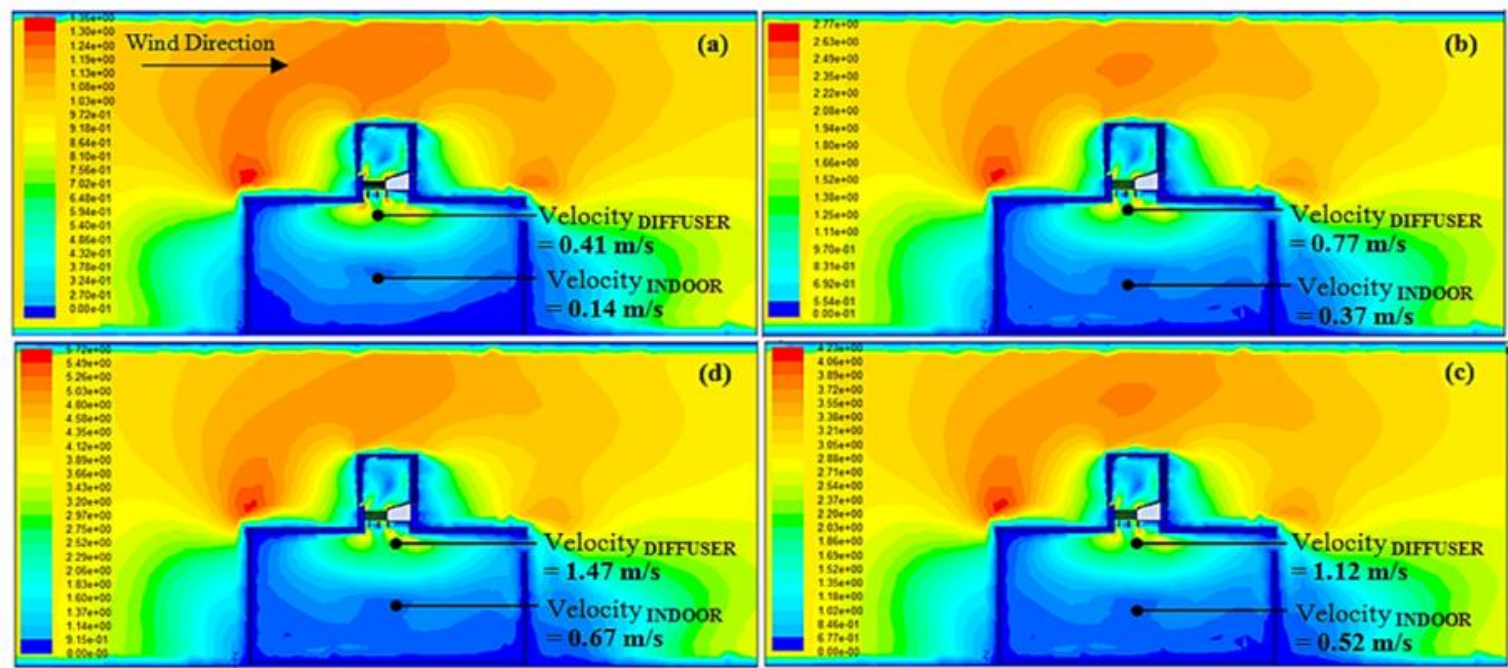

Figure 4 Velocity Contour Levels in the Test Room with an Inlet Velocity of: (A) 1 M/S (B) $2 \mathrm{~m} / \mathrm{s}$ (C) 3m/S (D) 4m/s

Figure 5 displays the pressure contour levels for the wind tower integrated with heat pipes. As expected, a region of positive pressure was created upstream of the wind tower while a region of negative pressure gradient was created downstream of the structure.
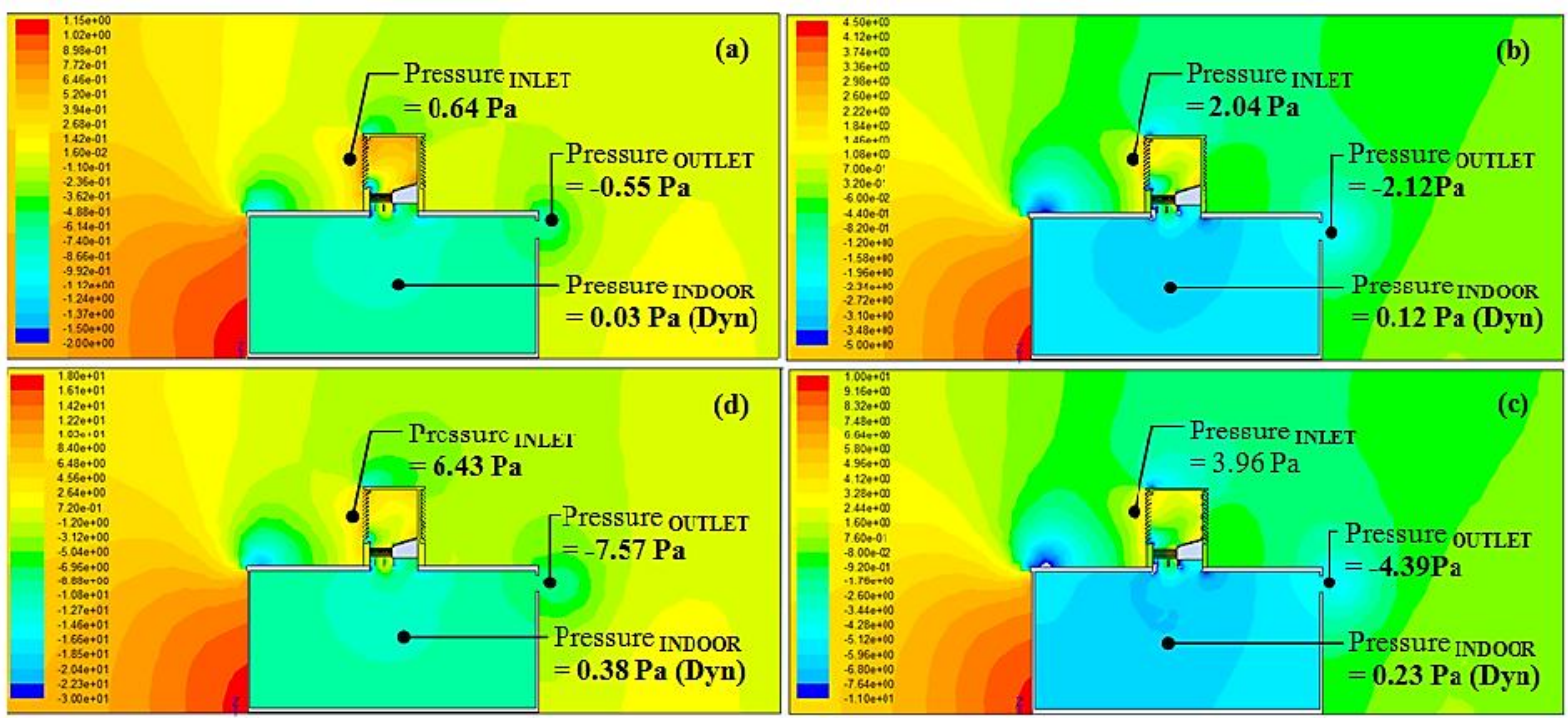

Figure 5 Pressure Contour Levels in the Test Room with an Inlet Velocity of: (A) $1 \mathrm{M} / \mathrm{S}$ (B) 2m/s (C) 3m/S (D) 4m/s 
In order to highlight the flow and thermal effectiveness of heat pipes, a direct comparison between a standard wind tower and a heat pipe assisted system was established. It was observed that at low external wind speed of $1 \mathrm{~m} / \mathrm{s}$ the heat pipe wind tower model barely supplied the minimum rate for a standard small classroom of 15 occupants (10L/s per occupant), though this was easily surpassed as the external velocity was increased [12]. The graphical representation of the air supply rates $(\mathrm{L} / \mathrm{s}$ per $\mathrm{m}^{2}$ and $\mathrm{L} / \mathrm{s}$ per occupant) using the standard model and heat pipe model are displayed in Figure 6. In general, it was observed that the standard model was able to provide nearly $26 \%$ higher amount of natural ventilation in comparison to the heat pipe model.

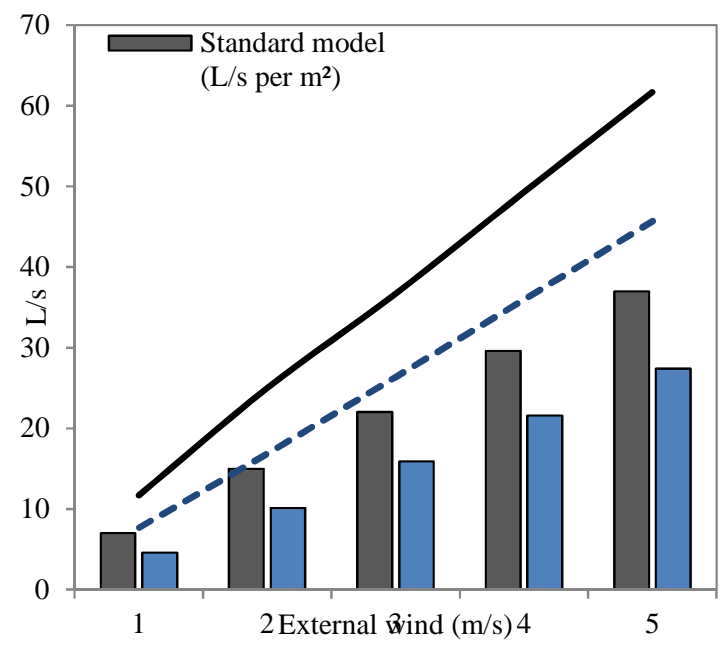

Figure 6 Comparisons of the Air Supply Rates of the Different Configurations at Different Wind Speeds

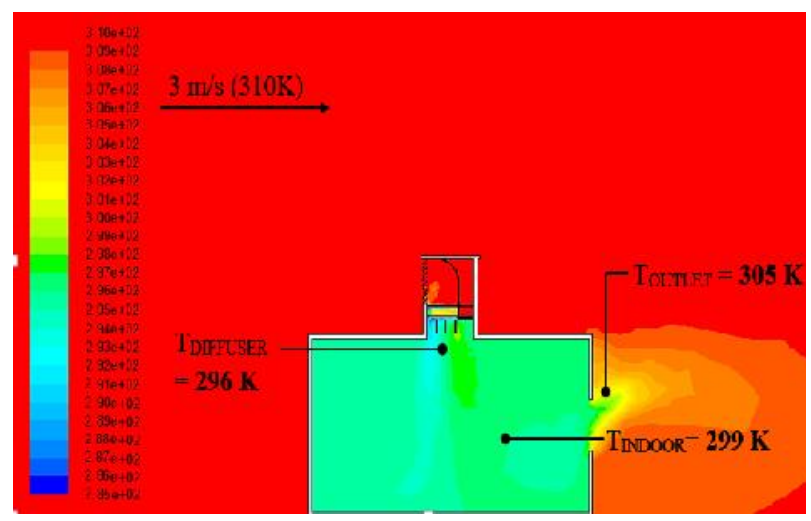

Figure 7 Temperature Distribution Achieved Inside the Test Room
Figure 7 displays temperature distribution inside the micro climate of the test room. At an external or source air temperature of $310 \mathrm{~K}\left(37^{\circ} \mathrm{C}\right)$, the average indoor air temperature profile was obtained at approximately $299 \mathrm{~K}$ $\left(25^{\circ} \mathrm{C}\right)$, displaying a reduction in air temperature of $11 \mathrm{~K}$ $\left(11^{\circ} \mathrm{C}\right)$ and highlighting the effectiveness of the heat pipe technology in achieving sustainable indoor thermal conditions.

\section{Conclusion}

For countries incorporating extreme climatic conditions, the utility of natural ventilation carries significant importance in reducing air-conditioning loads and its required power consumption for buildings and residential dwellings. In order to allow for fresh air and thermally comfortable temperatures, a novel integration between a wind tower and heat pipes for heat transfer was carried out in this study. Cylindrical heat pipes of optimised pitch distances were installed inside the passive terminal of the roof-mounted wind tower unit. The numerical investigation was carried out at wind speeds ranging from $1 \mathrm{~m} / \mathrm{s}$ to $5 \mathrm{~m} / \mathrm{s}$ using CFD to simulate and analyse the external air flow pattern and temperature distribution around and through the wind tower to the test room. The findings from the work highlighted that the proposed cooling system was capable of meeting the regulatory fresh air intake requirements per occupant of 10L/s. In addition, the results showed that a passive cooling capacity of $11 \mathrm{~K}$ was achievable when the system was subjected to inlet temperatures of $310 \mathrm{~K}$. The present work successfully classified the sustainable operation of natural ventilation systems in delivering energy-free cooling in regions encompassing hot and dry climatic conditions.

\section{References}

1. World Business Council for Sustainable Development (2009) Energy Efficiency in Buildings: Transforming the Market. WBCSD Report June 2009

2. U.S Department of Energy. Energy Efficiency and Renewable Energy (Online) 2014 Available from: http://www1.eere.energy.gov/buildings/commercial/hvac .html

3. Hughes BR, Chaudhry HN and Ghani SA, (2011). A review of sustainable cooling technologies in buildings, Renewable and Sustainable Energy Reviews 15, 31123120

4. Chaudhry HN, Hughes BR and Ghani SA, (2012). A review of heat pipe systems for heat recovery and renewable energy applications, Renewable and Sustainable Energy Reviews 16, 2249-2259

5. Chaudhry HN and Hughes BR, (2011). Computational analysis of dynamic architecture, Journal of Power and Energy, Proceedings of the Institution of Mechanical Engineers Part A 225, 85-95

6. Jones B and Kirby R, (2008) Quantifying the performance of a top-down natural ventilation Windcatcher, Building and Environment 44, 1925-1934 
7. Hughes BR, Calautit JK and Ghani SA, (2012) The Development of Commercial Wind Towers for Natural Ventilation: a review, Applied Energy 92, 606-627

8. Bouchahm Y, Bourbia F and Belhamri A, (2011) Performance analysis and improvement of the use of wind tower in hot dry climate, Renewable Energy 36, 898-906

9. Bahadori M, (1994) Viability of wind towers in achieving summer comfort in the hot arid regions of the Middle East, Renewable Energy 5, 879-892

10. Hughes BR, and Ghani S, (2007) An investigation of a windvent passive ventilation device against current fresh air supply recommendations, Energy and Buildings 40, 1651-1659.

11. Hughes BR and Ghani S, (2010) A numerical investigation into the effect of windventlouvre external angle on passive stack ventilation performance, Building and Environment, 45:1025-36.
12. Building Bulletin, Ventilation of School Buildings Regulations, Standards and Design Guidance 1, 20065 6: ISBN 011-2711642

13. Saber MH and Ashtiani HM, (2010). Simulation and CFD Analysis of heat pipe heat exchanger using Fluent to increase of the thermal efficiency, Proceedings of the 7th WSEAS International Conference on Heat and Mass Transfer, Cambrdige

14. Mehta U, (1991( Some aspects of uncertainty in computational fluid dynamics results, Journal of Fluids Engineering 113, 539-543.

15. Chung TJ, (2002). Computational Fluid Dynamics, Cambridge University Press; illustrated edition, ISBN0521594162 . 